\title{
Avaliação em Teatro: implicações, problemas e possibilidades
}

\author{
Beatriz A.V.Cabral
}

\section{Introdução}

autonomia do aluno na esfera da aquisiçãao e produção do conhecimento redefine os procedimentos tradicionais de avaliação. As implicações de avaliar seu desempenho em teatro residem na dimensão artística da atividade - é o teatro enquanto arte que torna a experiência ou o processo relevante educacionalmente. Esta relevância decorre do uso seletivo da linguagem e do gesto, do engajamento pessoal e emocional com imagens, símbolos e metáforas, da identificação com o outro. Em qualquer dos casos, a atividade se caracteriza como processo de construção e comunicação em grupo, através de parâmetros artísticos previamente definidos, mesmo quando transgredilos torna-se o objetivo do artista.

Se o foco no processo tem sido tradicionalmente privilegiado em educação, em oposição ao foco no produto (o espetáculo), a tendência hoje é considerar o processo como uma contínua comunicação de produtos parciais e temporários que se configuram como a base da avaliação.

A avaliação em educação, segundo Derek Rowntree, "pode ser pensada como aquela que ocorre quando uma pessoa, através da interação, direta ou indireta, com outra, conscientemente obtém e interpreta informações sobre o conhecimento, compreensão ou atitudes desta pessoa" (1977, p. 4). O professor ou diretor pode usar o resultado desta avaliação para preencher as exigências do sistema de ensino ou da produção, ou apenas para levar o processo à frente.

O desenvolvimento do processo depende da avaliação do que foi atingido até então. Assim, é possível dizer que a avaliação é fundamental mesmo para uma atividade centrada no processo, e em decorrência, central a qualquer abordagem curricular, uma vez que está associada à eficácia do ensino em termos de seu planejamento e estrutura, e à comunicação em termos de emissão e recepção de informações durante todas as etapas do trabalho.

Ao estruturar a atividade, estabelecer objetivos e selecionar estratégias, o professor está direcionando a atenção dos alunos para determinados aspectos do texto ou situação. Suas opções delimitam o campo de expressão dos participantes, e ampliam suas possibilidades ao prover um foco coletivo e introduzir informações. As contradições postas pela intervenção do professor no processo criativo do aluno tem sido o principal questionamento da avaliação.

Para Jon Nixon, a relação entre objetivos e avaliação inicia o debate sobre "esta tarefa vexatória de rotular os alunos" (1987, p. 51).

Beatriz A. V. Cabral é professora da UDESC e da UFSC; doutora em Artes-Drama pela University of Central England; membro da diretoria da ABRACE na gestão 2002-2004. 
Jonothan Neelands, por sua vez, observa que "ser muito definido e claro sobre as intenções e foco do trabalho, em drama, é negar aos alunos o poder e a experiência de serem artistas" (1990, p. 82); enquanto John O'Toole argumenta que a avaliação não deve ir além de suposiçôes explícitas "expressas nos objetivos das aulas e unidades de trabalho" (1992, p. 226).

A suposição de que intenções muito definidas inibem os alunos de serem artistas tem seu equivalente em outras áreas da educação. Rowntree observa que "os atos melhor intencionados podem produzir resultados diversos dos pretendidos [...]; nós deixamos de compreender o fenômeno estudado se nos preocuparmos apenas com os objetivos pré-identificados e desconsiderarmos os efeitos secundários” (1977, p. 35). Sobre esta questão, Elliot Eisner enfatiza: "uma coisa é perguntar, 'o aluno aprendeu o que ele ou eu pretendemos?'. Outra coisa é perguntar 'o que o aluno aprendeu?" (1972, p. 211).

Abrir a avaliação para o imprevisível não significa que não haja previsão sobre o que esperar do aluno quanto ao conhecimento, compreensão, habilidades e atitudes adquiridas. São estas expectativas que definem os objetivos, as estratégias e tarefas e tornam a avaliação relevante. Afinal, os objetivos estão fundamentados na suposição de que o propósito da educação não é apenas informar, mas criar oportunidades para que o aluno faça uso dos conhecimentos adquiridos em diferentes contextos e circunstâncias. Como argumenta Jerome Bruner, "nosso maior objetivo em ensinar uma disciplina não é levar o aluno a incorporar um conteúdo específico à sua mente, mas sim, ensiná-lo a participar no processo que torna possível a incorporação do conhecimento [...] conhecimento é um processo, não um produto" (apud Rowntree, 1977 , p. 97).

No ensino do teatro a dicotomia processo versus produto foi agravada por uma tendência em associar 'produto' a 'produção' (espetáculo), o que afastou a avaliação dos produtos parciais criados durante o processo. Como consequiência, estes perderam seu status de 'produtos' e com ele a possibilidade de ter sua eficácia objetivamente avaliada. Esta tendência, presente na abordagem contextualista do ensino da arte, que considera esta como meio para o ensino de conteúdos diversos, inviabiliza a avaliação em artes e como tal seu ensino, pois, como afirma David Hornbrook, "se espera-se que os alunos aprendam através do teatro, então o assunto a ser avaliado deve ser aquele que eles irão aprender e não o teatro em si” (1991, p. 125).

Entretanto, ao fazer teatro, a aprendizagem é em teatro - o tema ou o assunto não seria o mesmo se a forma artística fosse outra. Sem o conhecimento das formas e convenções teatrais é improvável que os alunos possam se beneficiar deste processo de aprendizagem. É a forma que viabiliza a expressão e a comunicação de conteúdos. Quanto melhor o aluno conhecer a forma artística, melhor será sua aproximação ao assunto em foco.

Para o desenvolvimento de estruturas próprias em uma determinada área do conhecimento - criação de analogias, novos significados - é necessário evitar associar os procedimentos de avaliação a objetivos de conteúdo previamente determinados. Assim, se a expectativa é que os alunos aprendam ao fazer teatro, o objeto de avaliação deve ser teatro. Ao formular objetivos expressivos, o professor está abrindo espaço para a performance pessoal e original do aluno, que será a base da avaliação.

Uma análise da função da avaliação em Drama e Teatro-Educação, baseada em publicaçôes inglesas do período de 1977 a 1992, ocasião da reforma curricular na Grã-Bretanha (Cabral, 1994), revelou padrōes de referência em períodos distintos: a priorização do experienciar e a avaliação coletiva do processo predominaram nos anos 1970; listas de objetivos associados à cognição, habilidades expressivas e comportamentos proliferaram na década de 1980 , na qual as dificuldades de avaliar foram computadas às implicaçôes de julgar a qualidade de trabalhos com base em sentimentos e intuição; análises conceituais no início dos anos 1990 salientaram as limitaçōes de se associar a avaliação em artes 
a objetivos definidos previamente. Em 1992, David Hornbrook lança uma proposta curricular com objetivos específicos a cada faixa etária e correspondentes expectativas de desempenho, acirrando o debate.

O mapeamento dos principais problemas associados à avaliação do aluno no decorrer de um processo dramático, apresentado a seguir, visa ampliar o debate sobre julgamentos de valor em teatro e as implicações de avaliar os altos e baixos dos processos de criação e ensaios. Uma vez que os textos comentados mostram mudanças na forma de abordar a avaliação no espaço de tempo investigado, a opção foi agrupá-los de acordo com seus focos de discussão.

\section{O 'drama' pode ser avaliado?}

Ao publicar o resultado da pesquisa Drama no Currículo: dos 10 a 16 anos, em 1977, McGregor, Tate e Robinson enfatizam que a avaliação só é indicada para julgamentos sobre o trabalho coletivo, e estes só podem ser feitos com base nos objetivos do professor em relação a um grupo específico. Para tanto, os autores sugerem aspectos que devem ser considerados antes da aula - prontidão do aluno; durante a aula - flexibilidade para aceitar mudanças e situações emergentes; e possiveis desdobramentos - outros tipos de aprendizagem além daquelas relacionadas ao teatro (McGregor et al., 1977, p. 95-6).

Uma segunda pesquisa sobre o teatro no currículo (Stabler, 1978, p. 209-14) focaliza as dificuldades em avaliar a expressão de sentimentos e respostas espontâneas. Os professores ouvidos reivindicam maiores opçôes metodológicas e reconhecem que a avaliação de um trabalho prático traz inúmeros problemas - evoca respostas originais e pessoais, requer material adicional (artes visuais, literatura), além da empatia e intuição do professor.

As abordagens apresentadas a seguir analisam as implicações em se avaliar o desempenho do aluno de drama/teatro devido ao caráter pessoal e temporal do produto das tarefas realizadas.
Para Gavin Bolton (1979), as implicações de avaliar mudanças de entendimento só podem ser testadas fora do contexto dramático, através da reflexão, enquanto mudanças de comportamento, tais como integridade e sensibilidade, só podem ser observadas algum tempo após o trabalho. O bom desempenho, segundo o autor, não está vinculado à aquisição de conhecimentos específicos, mas à maturidade pessoal.

Richard Courtney (1980, p. 78-80) vai além e lista as dificuldades da avaliação em drama: aprendizagens múltiplas tornam difícil discriminar açôes sem distorcer o quadro geral; medir um produto essencialmente temporal não acrescenta nada; o processo dramático consiste tanto de imaginação interior quanto de ação exterior e a avaliação se ocupa apenas do comportamento externo. Para não violar a "natureza holística do drama”, Courtney sugere um método de avaliação que inclui três etapas: Avaliação Diagnóstica (antes da aula) - concentração, sinceridade, absorção etc.; Avaliação Formativa (níveis de conhecimento do aluno) - forma dramática, papéis e modelos etc.; Avaliação Somativa (ao final do programa) - informações sobre aquilo que os alunos alcançaram.

$\mathrm{O}$ aspecto processual do drama é acentuado por Alan Lambert e Cecily O'Neill (1982, p. 145-46), para quem o maior problema da avaliação é o fato de o professor precisar ser conduzido por sinais exteriores para julgar o que pode ser basicamente uma experiência interior. Mudança de entendimento é difícil de avaliar, pois drama se refere a realidades imaginárias, não a eventos acabados. Entretanto, objetivos específicos para cada aula permitiriam examinar a aprendizagem emergente, o que pode ser medido e demonstrado em algum grau. Para eles, progressão não significa um aumento da competência técnica para usar o medium, mas o aumento do nível da complexidade naquilo que está sendo criado - a habilidade de descrever, analisar, interpretar e avaliar.

Pat Cook (1982, p. 37-45) propõe avaliar a aquisição de conhecimento através da análise do conteúdo da experiência. Ele questiona o 
tabu referente à subjetividade, e argumenta que esta não deveria ser removida dos procedimentos de avaliação, uma vez que o drama é uma atividade orientada por valores, contendo sólidos critérios baseados em interpretação descritiva e analítica e não em estratagemas estatísticos. Assim sendo, absorção, envolvimento, etc., são pontos de partida para a aquisição de conhecimentos e não atividades-fim.

Dorothy Heathcote (1985, p. 54-60) argumenta que o drama sempre requer a cristalização de idéias e que sua apresentação final deve ter uma "forma" capaz de ser compartilhada com os espectadores. Entretanto, segundo Heathcote, a cristalização de idéias e a possibilidade de compartilhá-las, quando concomitantes e baseadas em um mesmo texto, geralmente têm objetivos muito vagos, e a avaliação acaba se baseando equivocadamente nos aspectos de "mostrar" em vez de "experienciar".

É possível identificar acima uma mudança de parâmetros - a questão inicial, "pode-se avaliar Drama?", foi modificada e tornou-se mais precisa: "os alunos podem ser avaliados em Drama?" A alegação de que a mudança de entendimento e a dimensão temporal dos resultados apresentados dificulta a avaliação está, segundo os autores acima, baseada em três principais argumentos:

1) a mudança de entendimento surge da articulação de experiências imaginárias; depende da maturidade pessoal e não da aprendizagem em drama; usualmente está relacionada com pistas em vez de evidências;

2) o reconhecimento desta mudança depende do observador e varia de acordo com os valores do professor;

3) o drama não lida com realidades acabadas, mas com compromissos e conseqüências futuras; sua dimensão temporal implica em avaliar o que existe aqui e agora.

\section{Chamada à responsabilidade}

Em 1982, o Projeto Arte na Escola (Fundação Gulbenkian) considerou as seguintes implica- ções no tocante à responsabilidade do professor frente à avaliação: atenção à qualidade da experiência, às diferenças de valor, ao fato de que o conhecimento em drama está baseado no sentimento e na intuição.

As respostas a este projeto variam da não aceitação da avaliação em si (Neelands), à consideração da avaliação como um atendimento às exigências do sistema educacional (Haseman e O'Toole), ou a constatação da necessidade de promover cursos de semiótica para professores, a fim de ajudá-los a interpretar espetáculos teatrais (Hornbrook).

Jonothan Neelands enfatiza o drama como processo e a avaliação dentro do contexto da ficção, centrada na percepção dos alunos e suas expectativas sobre a continuidade da experiência. Seu argumento principal é que o drama, sendo uma forma de aprendizagem dialética e não didática, "está centrado no desenvolvimento de um processo através de questionamentos abertos" (1984, p. 56).

$\mathrm{Na}$ mesma perspectiva, Ken Byron observa que o drama em sala-de-aula refere-se a habilidades comuns para ler comportamentos e interagir que todos nós empregamos diariamente. Para ele, a forma mais eficaz de estimular a autonomia e responsabilidade em classe, é manter discussões de avaliação regulares, centradas em questôes tais como: "O que faz isto funcionar ou não? Como podemos lidar com este problema?" (1986, p. 153)

Para Jon Nixon (1987, p. 51-54), a questão sobre como avaliar drama, e mais ainda, se cabe avaliá-lo, é na realidade vexatória. Como alternativa, ele sugere a auto-avaliação e o relatório referente ao progresso do aluno a ser enviado aos pais. Para tanto, propõe um questionário para subsidiar a auto-avaliação e sugere que os professores preparem seus relatórios com base nos comentários dos alunos, a fim de focalizar as preocupaçôes de cada um.

John O'Toole e Brad Haseman (1988, p. II-III) enfatizam que julgar a qualidade do trabalho do aluno significa exclusivamente responder à demanda do sistema educacional. Eles 
consideram que julgamentos sobre respostas baseadas em sentimentos e crescimento emocional sempre trazem problemas, e para minimizálos os julgamentos devem ser relacionados com a expressão, apropriação, manipulação e controle do meio (medium). Os autores apresentam uma série de técnicas a serem usadas na avaliação, incluindo documentação dentro e fora do contexto dramático, análise de jornais elaborados pelos alunos, e reavaliação constante.

Norah Morgan e Juliana Saxton (1987, p. 189-213) apresentam listas de critérios para avaliação nas esferas comportamentais, instrucionais e prescritivas, a partir de uma perspectiva expressiva. Ao considerar a natureza subjetiva do avaliador, propóem a contribuição do aluno sendo avaliado, o qual deve estar ciente dos critérios utilizados. Avaliação, para as autoras, deve ser formativa, cumulativa e contínua e apesar de todas as implicações negativas, é um componente vital da aprendizagem, ajudando o professor a identificar os próximos passos e a obter evidência do desenvolvimento do aluno.

John McLeod (1986, p. 29-36) identifica quatro grupos de problemas:

1) subjetividade: os julgamentos representam os valores do avaliador;

2) evidência: relacionamento impreciso entre significado e ação;

3) validade: a avaliação de significados pessoais, pelo professor, deve ser questionada;

4) generalização: critérios de avaliação baseados em objetivos de aprendizagem não indicam ações específicas.

Para David Hornbrook (1989, p. 131), o conteúdo de uma aula é sempre escolha do professor e a proficiência nos elementos básicos da arte dramática é uma maneira de medir a progressão do aluno. $\mathrm{O}$ autor sugere dois modelos alternativos de avaliação: o primeiro compartilha uma base conceitual com Artes Visuais, Música e Dança, visando cursos que, através de módulos restauram o status artístico para apresentações escolares. O segundo pressupóe o desenvolvimento da apreciação, cuja avaliação pode ser facilitada através da utilização do mo- delo de Análise do Espetáculo proposto por Patrice Pavis.

A natureza holística do drama foi acentuada neste período como um processo contínuo, que requer um método dialético baseado em questionamento aberto, com pouco ou nenhum produto final, e respostas baseadas em sentimentos. A dificuldade posta para a avaliação, segundo estes autores (com exceção de Hornbrook), reside no fato de que a validade da tarefa de avaliar depende da natureza subjetiva do avaliador e do avaliado. Enquanto Morgan e Saxton apoiam a idéia de envolver o aluno na avaliação, equilibrando sua opinião com os julgamentos do professor, Hornbrook sugere o aperfeiçoamento do professor.

\section{A década de 1990}

O debate sobre avaliação na primeira metade dos anos 1990 contemplou e questionou as definiçōes tomadas na implementação do novo currículo (Education Reform Act - 1988). Por um lado, a grande maioria de teóricos e professores uniu-se contra a especificação de objetivos associados a expectativas de resultados, evocando seu efeito restritivo sobre o processo artístico. Por outro lado, houve quem considerasse que as declarações de expectativas são um exemplo de como a progressão e os resultados alcançados podem ser identificados em drama. Aspectos do subseqüente debate, mencionados abaixo, pontuam questóes sobre a natureza da atividade dramática.

Para Jonothan Neelands (1990, p. 82), os contextos institucionais que promovem um clima de prestação de contas baseado na execução de tarefas pré-determinadas e mesuráveis, pressionam o professor a direcionar o teatro para aspectos apenas instrumentais e esquecer ou desvalorizar aspectos expressivos. Em publicação mais recente, Neelands (1992, p. 64-6) aprofunda este questionamento, acrescentando que a aprendizagem em drama acontece através da experiência associada à reflexão pessoal e social sobre ela; portanto a forma artística é um 
importante foco - a cena pode ser trabalhada de diversas maneiras, cada uma irá iluminá-la a partir de uma perspectiva diferente.

Hornbrook (1991, p. 68-125), também em publicação posterior, afirma que a avaliação em artes é tanto possível quanto necessária e, se estruturada adequadamente, pode ser uma contribuição positiva para a arte na educação. Ele comenta a preocupação com a possibilidade de um programa de avaliação distorcer os propósitos curriculares ao concentrar-se nos aspectos da disciplina que mais prontamente facilitarão a avaliação. A fim de mostrar que é possível identificar progressão e identificação de resultados em drama, o autor propõe três objetivos específicos - fazer, representar e apreciar - e projeta a partir deles uma série de expectativas de resultados para cada série escolar.

A chamada à responsabilidade, segundo David Davis (1992), pressiona o desenvolvimento de objetivos de aprendizagem que incorporem as habilidades necessárias à criação artística. Por "habilidades" ele entende "a capacidade de organizar a forma com sucesso, a fim de realizar intenções". O problema, argumenta, é que a evidência de uma boa forma é justamente sua imprecisão, a qual permite o movimento ou deslocamento do conteúdo cada vez que o observador entra em contato com a obra. A forma tem que provocar um movimento no receptor. A conclusão de Davis é que o drama deve ser avaliado através da observação deste movimento, examinando como a forma permite a imprecisão do conteúdo.

John O’Toole (1992, p. 226-35) afirma que o drama é um meio oblíquo do fazer artístico, e não um espelho. Esta qualidade, associada à impossibilidade de controlar o ponto de partida do criador, reforça a imprevisibilidade do significado dos resultados apresentados. Assim, enquanto a educação formal se baseia em suposições explícitas expressas em objetivos específicos, a construção de significados em drama é acentuada tanto pela sua natureza oblíqua quanto pela atitude dos alunos. Nesse sentido, os significados artísticos mais profundos não são os mais universais, mas os mais específicos, uma vez que estes estão entrelaçados com o contexto real (a resposta dos alunos a este contexto). $\mathrm{O}$ contexto da ficção, ele acrescenta, permite que a realidade seja suspensa, mas ela permanece presente, e a força do drama está na ressonância entre os dois contextos.

Gavin Bolton propõe avaliações distintas para o comportamento dramático e para a performance. Para o primeiro caso, ele levanta quatro pontos referentes às ações dos participantes:

1) o conhecimento do conteúdo pelo aluno pode ser inadequado segundo as expectativas do adulto;

2) os participantes podem não estar envolvidos ou não ter interesse naquele processo ou tema;

3) um indivíduo no grupo pode estar minando o trabalho coletivo;

4) o contexto dramático pode ter perdido o foco, e, em decorrência, os alunos desviado sua atenção.

Bolton considera que o desempenho do aluno dependerá muito da forma pela qual o trabalho é proposto e conduzido. "Nós daremos nota baixa aos alunos porque o professor propôs o trabalho de forma inadequada, ou daremos notas altas porque eles se saíram bem apesar do professor?" (1992, p. 128-144).

Quanto à performance, Bolton questiona a eficácia de avaliar a originalidade de expressão, uma vez que a repetição é uma das características da mesma. A sugestão do autor é que os alunos sejam avaliados enquanto espectadores, a fim de desenvolver a apreciação, e incluir na avaliação os "altos e baixos" dos processos de investigação e ensaio.

Os autores acima advogam que objetivos específicos restringem a dimensão expressiva do trabalho artístico e que nenhuma tarefa de avaliação é capaz de responder à imprevisibilidade da significação.

A primeira destas alegações revela uma preocupação com a eventualidade do drama ser ensinado de acordo com a pedagogia tradicional, a 
qual exige dos professores um papel ativo na transmissão do conhecimento e uma avaliação segundo um modelo imposto de respostas válidas. A idéia de que ao especificar os objetivos o professor teria que medir a resposta dos alunos em face deles, sem deixar espaço para aspectos indeterminados ou expressivos, é um exemplo deste ponto de vista. A mesma preocupação está manifesta na idéia de que ao especificar os objetivos se está especificando os resultados a serem obtidos.

Estas posições refletem a preocupação geral, mencionada por Hornbrook, de que um programa de avaliação se concentre nos aspectos mais fáceis de avaliar, os quais, de acordo com Davis, significariam um retrocesso ao foco no exercício de habilidades, em detrimento do conteúdo.

\section{Reflexão final}

A revisão bibliográfica mostra que as dificuldades decorrentes das propostas para avaliação em teatro resultam da compreensão conceitual de seus autores sobre a natureza dos processos de criação e recepção e não do conteúdo programático oferecido. Uma análise dos argumentos apresentados a favor ou contra a avaliação evidencia problemas de conceituação que podem ser agrupados de acordo com as dicotomias que subscrevem:

1) intenção X expressão e a equivalente forma X conteúdo - problemas de evidência para se avaliar uma manifestação artística. Por exemplo, tentar avaliar a intenção dos atores, argumentar que a preocupação com a forma revela desconsideração com o conteúdo. Para estes autores, o foco na intenção estaria centrado não no pro- duto, mas nas causas que interferiram na sua criação. Duas questôes estão subjacentes: a primeira relaciona-se com alternativas metodológicas para auxiliar os alunos na busca pela melhor expressão, a segunda relaciona-se com ética - as formas de abordar os julgamentos de valor em público. É aqui que o esclarecimento do conceito de intenção é importante, pois intenções e conceitos são culturalmente historicizados.

2) subjetividade X objetividade - refere-se à tradição, na cultura ocidental, de associar as formas de expressão exclusivamente à visão pessoal do artista e a interpretação a uma questão de gosto. O subjetivo aqui aparece dissociado de um contexto objetivo, no nível da realidade e da ficção. Nesse sentido, a expressão subjetiva diferencia-se da expressão individual, a qual embora particular a um indivíduo, refere-se a elementos que podem ser objetivamente observados e, portanto, abertos à argumentação. Essa dicotomia revela a tendência para avaliar comportamentos em vez de desempenho artístico e o receio de que os julgamentos emitidos sejam considerados verdadeiros e definitivos, em vez de evidência da atuação do aluno naquele período.

3) intuição $X$ conhecimento - trabalhos e narrativas pobres, assim como falta de coerência e soluções deus ex machina estão usualmente relacionados com processos justificados como sendo baseados na intuição. Dissociar a intuição do conhecimento inviabiliza não só a avaliação, mas a própria educação em artes. Entretanto, a importância da avaliação torna-se ainda maior aqui, uma vez que tornará o artista consciente de aspectos do seu trabalho que possam ter sido não intencionais ou acidentais. 


\section{Referências bibliográficas}

BOLTON, Gavin. Towards a Theory of Drama in Education. Londres: Longman, 1979. New Perspectives on Classroom Drama. Hemel Hempstead: Simon \& Schuster, 1992.

BYRON, Ken. Drama in the English Classroom. Londres: Methuen, 1986.

CABRAL, Beatriz. Towards a Reader-Oriented Assesment in Drama in Education. (Tese de doutorado). University of Central England, 1994.

COOK, Pat. Evaluating Drama. 2D, v. 2, n. 1, p. 37-45, Autumn 1982.

COURTNEY, Richard. The Dramatic Curriculum. Londres: Heinemann, 1980.

DAVIS, David. The Relationship Form-Content. Mimeo. 1993.(1987, p. 51-54)

EISNER, Elliot. Educating Artistic Vision. Londres: MacMillan, 1972.

HASEMAN, Brad; O’TOOLE, John. Dramawise: an introduction to GCSE drama. Londres: Heinemann, 1988.

HEATHCOTE, Dorothy. Signs and Portents?. Scypt Journal, n. 9, p. 18-28, Jan. 1980.

HORNBROOK, David. Education and Dramatic Art. Oxford: Blackwell, 1989. Education in Drama. Londres: The Falmer Press, 1991.

LAMBERT, A.; O’NEILL, C. Drama Structures. Londres: Hutchinson, 1985.

MCGREGOR, L.; TATE, M.; ROBINSON, K. Learning Through Drama. Londres: Heinemann, 1977.

MCLEOD, John. Problems in Assessing Drama. 2D, v. 5, n. 2, p 29-36, 1986.

MORGAN, Norah; SAXTON, Juliana. Teaching Drama: “a mind of many wonders...”. Londres: Hutchinson, 1987.

NEELANDS, Jonothan. Making Sense of Drama. Londres: Heinemann, 1984.

. Structuring Drama Work. Cambridge University Press, 1990.

. Learning through Imagined Experience. Londres: Hodder \& Stoughton, 1992.

NIXON, Jon. Teaching Drama. Londres: MacMillan, 1987.

O’TOOLE, John. The Process of Drama: negotiating art and meaning. Londres: Routledge, 1992.

ROWNTREE, Derek. Assessing Students: how shall we know them? Londres: Harper and Row, 1977. 